\title{
DOES PREOPERATIVE TIBIAL TUBEROSITY - TROCHLEAR GROOVE DISTANCE EFFECT ON POSTOPERATIVE PATELLAR INSTABILITY IN THE PATIENTS WITH KNEE ARTHROPLASTY DUE TO MEDIUM-ADVANCED KNEE OSTEOARTHRITIS?
}

\author{
Turker Oguz, ${ }^{1}$ Cevik Nazan, ${ }^{1}$ Akalın Yavuz, Ozturk Alpaslan, ${ }^{1}$ \\ Durmus Yavuz, ${ }^{2}$ Sahin Hikmet ${ }^{1}$ \\ ${ }^{1}$ Health Science University Bursa, Yuksek Ihtisas Research and Training Hospital, \\ Department of Orthopaedics and Traumatology, Bursa, Turkey \\ ${ }^{2}$ Health Science University Bursa Yuksek Ihtisas, Research and Training Hospital, \\ Department of Radiology, Bursa, Turkey
}

Primljen/Received 22. 04. 2020. god.

Abstract: Objectives: Determining tibial tubercle-trochlear groove distance range as measured before the operation in the patients to whom total knee prosthesis will be applied due to mid to advanced level of osteoarthritic and seeing the post-operative variations in tibial tubercle-trochlear groove distance and evaluating whether it has any impact on the patellofemoral instability that might develop after the operation. 46 knees planned to be applied total knee prosthesis due to mid-advanced level of osteoarthritic were examined.

Methods: In the preoperative and postoperative magnetic resonance images MRI routinely taken, tibial tubercle-trochlear groove distance was measured. Later it was examined whether there was correlation between these preoperative and postoperative tibial tubercle-trochlear groove measurements and the data recorded before operation.

Results: Preoperative tibial tubercle-trochlear groove distance was found to be $8.83 \pm 3.54$, postoperative tibial tubercle-trochlear groovedistance was found to be $8.30 \pm 3.89$ and preoperative-postoperative tibial tubercle-trochlear groove variation was found to be 0,52 $\pm 3,64$ ( $\mathrm{p}=0,337)$. In the patients whose alignment was 10 degrees or less, Pre-Op tibial tubercle-trochlear groove distance was measured as $8.74 \pm 3.18$ and in the patients whose alignment was more than 10 degrees, it was measured as $8.89 \pm 3,83(\mathrm{p}=0.888)$. In the patients whose alignment was 10 degrees or less, Post-Op tibial tubercle-trochlear groove distance was measured as $8.00 \pm 2.85$ and in the patients whose alignment was
Prihvaćen/Accepted 06. 06. 2020. god.

more than 10 degrees, it was measured as $8.52 \pm 4.52$ $(p=0.661)$. In the patients whose alignment was 10 degrees or less, tibial tubercle-trochlear groove distance variation was measured as $0.74 \pm 3.25$ and in the patients whose alignment was more than 10 degrees, it was measured as $0.37 \pm 3.95(\mathrm{p}=0.741)$.

Coclusion: As a result, although tibial tubercle-trochlear groove distance was observed with a great variation in the osteoarthritic knees at stage 3-4, it was nonetheless measured within normal limits and Post-Op variation was not meaningful. Since this is the first study in the literature on the measurement of tibial tubercle-trochlear groove distance in the total knee prosthesis applications, we hope that it would shed some light on similar studies to be conducted in the future.

Key words: Knee biomechanics, Tibial tubercle, Trochlear groove, Total knee arthroplasty, Patellar instability.

\section{INTRODUCTION}

Osteoarthritic (OA) was defined by the American College of Rheumatology (ACR) as the heterogeneous group of disorders causing symptoms in the joint due the degenerated structure of the joint cartilage and resulting in alterations in the bones nearby the joint (1). It is mostly seen in the knee joint (2). Knee joint arthrosis is a pathology commonly observed in $10 \%$ of the population older than 55 years. Advanced stage of osteoarthritic causes severe restrictions in the functions of the knee joint along with strong pain. A treatment option is total knee arthro- 
plasty (TKA) and it is known as a final solution in eliminating the pain felt by the patient, helping him/her to regain his/her normal bodily functions. Number of total knee prosthesis (TKP) applied is increasing in parallel to prolonged lifetimes and increased rate of obesity. In the period 2010-2014, total 283.400 primary TKP was applied in Turkey and it was determined that these figures increased every year (3). Reason of approximately $12 \%$ of the revisions was found to be patellofemoral disorders.

Anterior knee pain felt after TKA is one of the most important problems observed in $20 \%$ of the patients $(4,5)$. Recent studies made on cadaver, along with biomechanical research showed that main reason of the anterior knee pain and patellar alignment problems was the misalignment of femoral and tibial component $(6,7)$. Factors causing patellofemoral instability are excessive femoral anteversion, genu valgum, genu recurvatum, joint hyperlaxity, patella alta, high Q angle, patellar dysplasia, trochlear dysplasia, high tibial tubercle-trochlear groove (TT-TG) distance $(8,9,10)$. Acute or chronic patella subluxation, repeated patella dislocation and chronic patella dislocation are all known as patellofemoral joint instabilities (9).

However; there are some patients in whom exact reason of this instability cannot be explained $(5,6,11)$. Patellofemoral motion is statically and dynamically affected by many factors. While static factors include rotation of femoral and tibial component, size of patellar implant, trochlear groove shape of the femoral implant and soft tissue balance, dynamic factors depend on the effect of the quadriceps muscle during the motion of the knee joint and on its size and TT-TG distance is one the static indicators affecting the patellofemoral motion $(12,13)$.

In many studies assessing the TT-TG distance, it was said that values considered as normal might change $(14,15)$. When TT-TG distance is $>15 \mathrm{~mm}$, it is considered abnormal and when it is $>20 \mathrm{~mm}$, it is considered pathologic (16). TT-TG distance has been observed as pathologic in the patients suffering from patella dislocation and anterior knee pain (17). However; there is no final consensus on the TT-TG distance variation in the osteoarthritic knees. In addition to certain studies confirming that no difference was measured in TT-TG distancesbetween the osteoarthritic knees and normal knees, there is research in which these measurements resulted in great variations, bringing a strong need for the preoperative measurement of TT-TG distance in order to achieve better results $(13,14)$.

This study aims to determine the TT-TG distance range measured in the patients preoperative and see the postoperative variation in TT-TG distance in order to evaluate whether this variation has any effect on the patellofemoral instability that might potentially developed in the patient and on the knee functions.

\section{METHODS}

46 TKA applications performed in our clinic with different surgeons in the period (November 2017-November 2018) were prospectively examined. Male and female patients aged 50-85 with mid-advanced level of knee osteoarthritic were included into the study group. Patients on whom TKA was performed after a diagnosis of rheumatoid arthritis, patients on whom revision TKA was performed, patients who had sequencing operation before around the knee, patients operated before due to patellofemoral instability and patients with valgus knee were not included into the study. 46 knees of total 39 patients were included into the study. The average age of the patients was $66.89 \pm 7.49$ and $41 \mathrm{pa}-$ tients were female, while 5 was male. 25 of these 46 knees $(54,3 \%)$ was right knee and $21(45,7 \%)$ was left knee. Bilateral TKA was performed on 7 patients.

In all patients included into the study, the knee was opened with median parapatellar arthrotomy and patellar surface was not replaced in any of the patients. All of the implants used in the operations had posterior stabilized design and prosthesis of different brands were used. While femoral rotation alignment was made on some patients using space balancing technique, surgery was performed on some other patients using measured resection technique. Operations were performed on the patients in a single center by different surgeons. Preoperative physical examination findings, sequence, joint range of motion (JRM), Knee Society Score (KSS) knee and function points, Western Ontario and McMaster Universities Osteoarthritis Index (WOMAC) score, length, weight, additional diseases and knee osteoarthritis level according to radiographic staging of Kellgren-Lawrence (18) were recorded.

After detailed anamnesis and physical examination of the patients in the preoperative phase, radiographic and laboratory examinations were performed. As radiographic examination, compared two-directional knee graphics and knee MRI images were taken by applying load on the foot. With the knee radiographies, sequence measurement and osteoarthritis stagingwas performed, while TT-TG distance was measured on the MRI images taken with a MR device branded GE Healthcare, model 1.5 Tesla Signa. Measurement of TT-TG distance was made on axial sections as described by Wittstein and friends (19). Measurements were performed by 2 experienced orthopaedics surgeons. In order to evaluate this distance, midpoint of the site where patellar tendon grips the tuberosity tibia was marked and later deepest point of the cartilaginous part of the trochlear groove was marked. By taking as a reference posterior femoral condylar line, a perpendicular line was drawn between the both two marked points and the ref- 


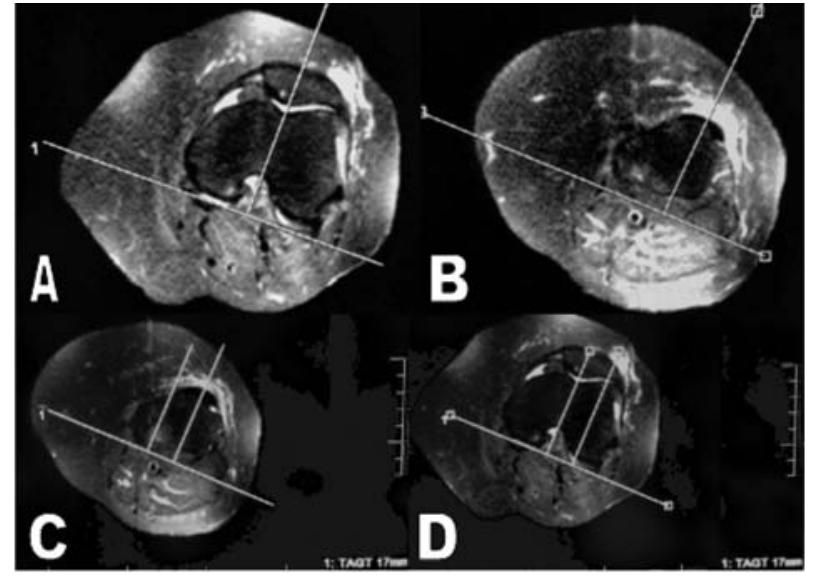

Figure 1. Pre-op MR Assessment:A.Perpendicular drawn from the deepest part of the trochlear groove by taking as a reference posterior condylar axis B. Perpendicular drawn from the midpoint of the part where patellar tendon grips TT to the posterior condylar axis, C. Image of the distance between two perpendiculars $(11 \mathrm{~mm})$ in the TT section, D. Image of the distance between two perpendiculars $(11 \mathrm{~mm})$ in the trochlear groove section

erence line. Then the distance between these two perpendicular lines was measured in order to determine TO-TG distance (Figures 1 and 2). Postoperative knee MRI was repeated in all patients. In order to avoid prevention of measurement because of the metal artifact, a postoperative MRI imaging was performed in MAVRIC sequence by using GE Healthcare branded 1.5 Tesla Signa model MRI device and TT-TG distance was measured and recorded with the same technique used in preoperative phase. The patients were evaluated in the postoperative $6^{\text {th }}$ month and their joint range of motion, WOMAC knee and function scores and KSS scores were recorded.

Later all data were analyzed by using SPSS 20.0 package program. Descriptive statistics were expressed

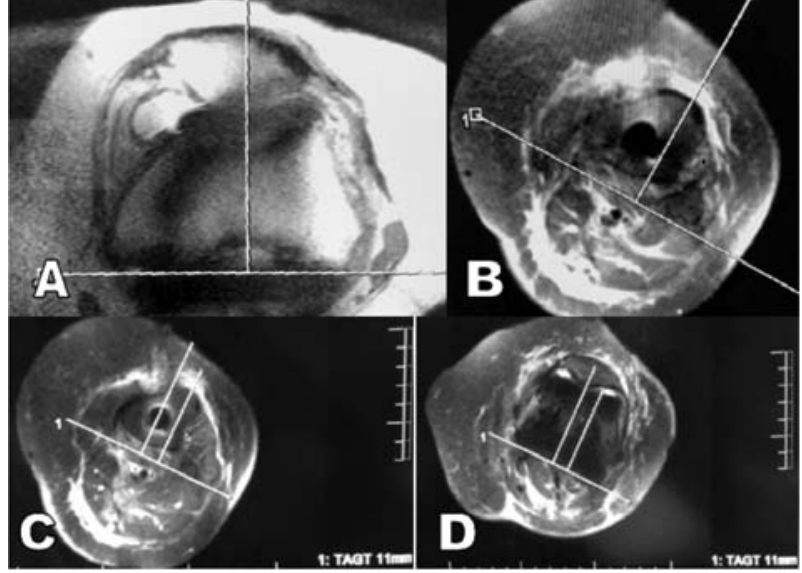

Figure 2. Post-op MR Assessment:A. Perpendicular drawn from the deepest part of the trochlear groove by taking as a reference posterior condylar axis B. Perpendicular drawn from the midpoint of the part where patellar tendon grips TT to the posterior condylar axisC. Image of the distance between two perpendiculars $(17 \mathrm{~mm})$ in the TT sectionD. Image of the distance between two perpendiculars $(17 \mathrm{~mm})$ in the trochlear groove section

as \pm standard deviation (SD), median (minimum-maximum value), $\mathrm{n}$ and $\%$. Compatibility of numerical variants to the normal distribution was examined using coefficients of skewness. Preoperative and postoperative TT-TG distances were compared in the dependent groups by using T-test. For the analyses involving two variables; T-test, Mann-Whitney U test, unilateral ANOVA (post hocLSD), chi-square test and Pearson correlation analysis were used in the independent groups. $P$ value $<$ 0,05 was considered as statistically meaningful.

\section{RESULTS}

Main conclusion criterion in this research was TT-TG distance. TT-TG distance was measured preoperatively and postoperatively and difference in betwe-

Table 1. Examined Variables

\begin{tabular}{|l|c|c|c|c|c|c|c|c|c|}
\hline & & & \%95 GA & & & \%95 GA & & \\
\cline { 2 - 10 } & Ave. & SD & Anterior & Posterior & Ave. & Anterior & Posterior & Min. & Max. \\
\hline Length $(\mathrm{cm})$ & 158.87 & 5.81 & 157.14 & 160.60 & 160.00 & 160.00 & 165.00 & 150.00 & 170.00 \\
\hline Weight $(\mathrm{kg})$ & 81.76 & 13.58 & 77.73 & 85.79 & 80.00 & 80.00 & 90.00 & 60.00 & 115.00 \\
\hline BMI & 32.44 & 5.61 & 30.77 & 34.10 & 31.25 & 31.23 & 33.30 & 25.71 & 48.89 \\
\hline Pre-op TT-TG (mm) & 8.83 & 3.54 & 7.78 & 9.88 & 8.00 & 7.00 & 10.00 & 2.00 & 18.00 \\
\hline Post-op TT-TG (mm) & 8.30 & 3.89 & 7.15 & 9.46 & 8.00 & 7.00 & 10.00 &, 00 & 18.00 \\
\hline Pre-op and post-op TT-TG difference (mm) & 0.52 & 3.64 & -0.56 & 1.60 & 0.00 & 0.00 & 2.00 & -8.00 & 9.00 \\
\hline Pre-op flexion angle & 100.67 & 15.90 & 95.89 & 105.44 & 95.00 & 90.00 & 100.00 & 80.00 & 135.00 \\
\hline Pre-op extension angle & -2.67 & 4.47 & -4.01 & -1.32 & 0.00 & 0.00 & 0.00 & -15.00 &, 00 \\
\hline Pre-op KSS knee scoring & $38-64$ & 18.01 & 33.23 & 44.06 & 35.00 & 32.00 & 45.00 & -2.00 & 84.00 \\
\hline Pre-op KSS keen function scoring & 42.00 & 25.41 & 34.36 & 49.64 & 45.00 & 45.00 & 60.00 & 0.00 & 95.00 \\
\hline Pre-op WOMAC score & 66.87 & 17.69 & 61.56 & 72.18 & 65.62 & 61.45 & 71.87 & 4.16 & 93.75 \\
\hline Alignment & 12.09 & 4.88 & 10.64 & 13.53 & 11.00 & 10.00 & 13.00 & 2.00 & 30.00 \\
\hline
\end{tabular}

(BMI: Body Mass Index Pre-op:Preoperative TT-TG: Tibial Tubercle-Trochlear Groove. Post-op: Postoperative WOMAC: Western Ontario and Mcmaster Universities Osteoarthritis. Index KSS: Knee Society Score Ave: Average) 
en was compared. Data relating to 46 knees of 39 patients were analyzed. Bilateral TKA was performed on 7 patients. In this study, 34 patients were female and 5 patients were male and average age was calculated as $66.48 \pm 7.49 .25$ knees included into the study were operated from the right side (54.3\%) and 21 knees were operated from the left side (45.7\%). Osteoarthritis stage of twelve patients (26.1\%) was Kellgren-Lawrence (KL) stage 3 , while it was stage 4 in 34 patients (73.9\%). Descriptive statistics relating to the numerical variables examined are shown in Table 1. Other variables examined in this study included age (year), operated side (right-left), length $(\mathrm{cm})$ and weight $(\mathrm{kg})$ and body mass index (BMI). In addition, preoperative and postoperative flexion and extension angle, KSS knee scoring, KSS function scoring, WOMAC score, osteoarthritis stage and sequence were recorded (Table 2).

No meaningful difference was determined in terms of pre-op and post-op TT-TG difference between the TT-TG values of female and male patients and operative interventions from the right and left side of the knee $(\mathrm{p}=0.808)$.

No meaningful difference was determined in terms of pre-op TT-TG distance, post-op TT-TG distance and pre-op and post-op TT-TG difference according to the specific osteoarthritis stage. TT-TG distance was reduced by $1.21 \mathrm{~mm}$ in average in the patients with stage 3 osteoarthritis as compared to the stage 4 patients but it was not found statistically meaningful ( $p$ $=0.328$ ).

While varus alignment of 19 patients was 10 degrees and less, it was more than 10 degrees in 27 patients. According to the varus alignment grouping, the difference between Pre-op TT-TG (p: 0.888), Post-op TT-TG (p: 0.661) and Pre-op and Post-op TT-TG (p:0.741)differences was not statistically meaningful.
When pre-op TT-TG distances are classified as $<$ $10 \mathrm{~mm}, 11-15 \mathrm{~mm}$ and $>15 \mathrm{~mm}$, a meaningful difference was determined between the groups in terms of Post-op TT-TG (meaningful on the limit), Pre-op and Post-op TT-TG difference (p:0.013) and Pre-op flexion angle (0.009) (Table 2).

When Pre-op TT-TG distances are grouped, although there was no meaningful difference between the groups in terms of length, a meaningful difference was determined in terms of weight (p:0.016) and BMI (p:0.004).

Upon an examination of the correlations between the variables, a statistically meaningful correlation was seen in the Pre-op TT-TG distance with the Post-op TT-TG distance and Pre-op and Post-op TT-TG distance difference (Table 3 ).

The difference between the Pre-op and Post-op TT-TG distance measurements was $0.52 \pm 3.64 \mathrm{~mm}$ and this difference was not found statistically meaningful $(t=0.971 ; p=0.337)$. A linear regression model was created to examine the independent factors affecting the Pre-op and Post-op TT-TG difference. In the model into which BMI, Pre-op TT-TG, Pre-op flexion angle, Pre-op extension angle, Pre-op KSS knee scoring, Pre-op KSS knee function, Pre-op WOMAC and alignment was integrated, only Pre-op TT-TG values were determined to be independent indicator $(\mathrm{p}=$ $0.024)$.

Upon comparison of post-op flexion, post-op extension, post-op KSS knee score, post-op KSS knee function and post-op WOMAC scores according to pre-op TGS-TG distance categories by using unilateral ANOVA test, a meaningful difference was determined between the groups in terms of post-op extension angle $(p=0.02)$. When Pre-op TT-TG distance increases, post-op extension angle decreases.

Table 2. Comparison of various scores according to the pre-op TT-TG distance categories

\begin{tabular}{|c|c|c|c|c|c|c|c|c|}
\hline \multicolumn{9}{|c|}{ Pre-op TT-TG } \\
\hline & \multicolumn{2}{|c|}{$<10 \mathrm{~mm}$} & \multicolumn{2}{|c|}{$11-15 \mathrm{~mm}$} & \multicolumn{2}{|c|}{$>15 \mathrm{~mm}$} & \multirow{2}{*}{$\mathrm{H}^{*}$} & \multirow{2}{*}{$\mathbf{P}$} \\
\hline & Ave. & SD & Ave. & SD & Ave. & SD & & \\
\hline Post-op TT-TG (mm) & 7.20 & 3.59 & 10.43 & 3.92 & 10.00 & 1.41 & 5.961 & 0.051 \\
\hline Pre-op and Post-op TT-TG diff. (mm) & -0.50 & 3.15 & 1.71 & 3.47 & 7.50 & 2.12 & 8.625 & 0.013 \\
\hline Pre-op flexion angle & 98.10 & 13.98 & 108.93 & 16.78 & 80.00 & 0.00 & 9.492 & 0.009 \\
\hline Pre-op extension angle & -1.72 & 3.60 & -4.29 & 5.50 & -5.00 & 7.07 & 3.196 & 0.202 \\
\hline Pre-op KSS knee scoring & 40.00 & 16.36 & 37.43 & 22.22 & 27.50 & 6.36 & 1.983 & 0.371 \\
\hline Pre-op KSS knee function & 45.17 & 23.39 & 37.86 & 29.33 & 25.00 & 28.28 & 2.012 & 0.366 \\
\hline Pre-op WOMAC score & 65.58 & 15.05 & 69.49 & 23.67 & 67.18 & 0.74 & 1.708 & 0.426 \\
\hline Alignment & 11.90 & 4.40 & 12.50 & 6.21 & 12.00 & 1.41 & 0.184 & 0.912 \\
\hline
\end{tabular}

(Pre-op:Preoperative, TT-TG: Tibial Tubercle-Trochlear Groove, Post-op: Postoperative, WOMAC: Western Ontario and Mcmaster Universities Osteoarthritis Index, KSS: Knee Society Score.) 
Table 3. Correlation analysis between studied variables

\begin{tabular}{|l|l|c|c|c|c|c|c|c|c|c|}
\hline & & 1 & 2 & 3 & 4 & 5 & 6 & 7 & 8 & 9 \\
\hline 0-BMI & $\mathrm{R}$ & $\mathbf{0 . 3 4 8}$ & 0.250 & 0.071 & 0.274 & -0.105 & -0.101 & -0.203 & 0.191 & 0.020 \\
& $\mathrm{P}$ & $\mathbf{0 . 0 1 8}$ & 0.094 & 0.640 & 0.068 & 0.494 & 0.508 & 0.181 & 0.208 & 0.897 \\
\hline 1-Pre-op TT-TG (mm) & $\mathrm{R}$ & & $\mathbf{0 . 5 2 1}$ & $\mathbf{0 . 4 1 4}$ & 0.000 & -0.222 & -0.163 & -0.208 & 0.090 & 0.033 \\
& $\mathrm{P}$ & & $<\mathbf{0 . 0 0 1}$ & $\mathbf{0 . 0 0 4}$ & 0.998 & 0.142 & 0.284 & 0.171 & 0.558 & 0.827 \\
\hline 2-Post-op TT-TG (mm) & $\mathrm{R}$ & & & $\mathbf{- 0 . 5 6 1}$ & 0.043 & 0.108 & 0.095 & 0.176 & $\mathbf{- 0 . 3 3 7}$ & 0.139 \\
& $\mathrm{P}$ & & & $<\mathbf{0 . 0 0 1}$ & 0.780 & 0.481 & 0.536 & 0.248 & $\mathbf{0 . 0 2 3}$ & 0.356 \\
\hline 3-Pre-op and AS TT-TG & $\mathrm{R}$ & & & & -0.047 & $\mathbf{- 0 . 3 4 4}$ & -0.270 & $\mathbf{- 0 . 4 0 4}$ & $\mathbf{0 . 4 6 1}$ & -0.116 \\
difference (cm) & $\mathrm{P}$ & & & & 0.758 & $\mathbf{0 . 0 2 1}$ & 0.073 & $\mathbf{0 . 0 0 6}$ & $\mathbf{0 . 0 0 1}$ & 0.441 \\
\hline 4-Pre-op flexion angle & $\mathrm{R}$ & & & & & -0.182 & $\mathbf{0 . 3 2 5}$ & -0.041 & 0.065 & -0.021 \\
& $\mathrm{P}$ & & & & & 0.231 & $\mathbf{0 . 0 2 9}$ & 0.788 & 0.671 & 0.893 \\
\hline 5-Pre-op extension angle & $\mathrm{R}$ & & & & & & 0.128 & 0.203 & -0.228 & 0.023 \\
& $\mathrm{P}$ & & & & & & 0.403 & 0.181 & 0.132 & 0.878 \\
\hline 6-Pre-op KSS knee scoring & $\mathrm{R}$ & & & & & & & $\mathbf{0 . 5 4 6}$ & $\mathbf{- 0 . 5 1 5}$ & $\mathbf{- 0 . 5 1 8}$ \\
& $\mathrm{P}$ & & & & & & & $<\mathbf{0 , 0 0 1}$ & $<\mathbf{0 , 0 0 1}$ & $<\mathbf{0 , 0 0 1}$ \\
\hline 7-Pre-op KSS knee scoring & $\mathrm{R}$ & & & & & & & & $\mathbf{- 0 . 7 8 5}$ & 0.072 \\
& $\mathrm{P}$ & & & & & & & & $<\mathbf{0 , 0 0 1}$ & 0.636 \\
\hline 8-Pre-op WOMAC & $\mathrm{R}$ & & & & & & & & & -0.148 \\
& $\mathrm{P}$ & & & & & & & & & 0.333 \\
\hline 9-Sequence & $\mathrm{R}$ & & & & & & & & & \\
\hline & $\mathrm{P}$ & & & & & & & & & \\
\hline
\end{tabular}

1-Pre-op TT-TG (mm); 2-Post-op TT-TG (mm); 3-Pre-op ve Post-op TT- TG difference (mm); 4-Pre-op flexionangle; 5-Post-op extension angle; 6-Pre-op KSS knee scoring; 7-Pre-op KSS knee function, 8-Pre-op WOMAC; 9-Sequence (BMI: Body Mass Index, Pre-op: Before surgery, TT-TG: tibial tubercle-trochlear groove, Post-op: After surgery, WOMAC: Western Ontario and Mcmaster Universities Osteoarthritis Index, KSS: Knee Society Score.)

Upon an examination of the correlation between post-op TT-TG distance categories and post-op extension angle, knee scoring and WOMAC scores, it was determined that post-op WOMAC scores was different between the groups $(p=0.005)$. When Post-op TT-TG distance increases, post-op WOMAC score decreases.

Upon an examination of the correlation between pre-op post-op TT-TG distance difference and post-op extension angle, KSS knee scoring and WOMAC scores, a meaningful correlation was determined in terms of post-op extension angle, post-op KSS knee function and post-op WOMAC scores. While a negative correlation was observed between the Pre-op Post-op TT-TG distance difference and post-op extension angle and post-op KSS knee function, a positive correlation with the post-op WOMAC scores was noticed.

\section{DISCUSSION}

Generally in most of the societies, rate of knee and hip osteoarthritis in population older than 65 is approximately $40 \%$ and knee osteoarthritis is more common than hip osteoarthritis. In patients with advanced stage of knee osteoarthritis, TKA is a frequently used surgery operation with high success rate and it reduces the pain and develops the knee function (20). Patellar instability that might develop after TKA is a serious complication disrupting functional results and causing revision surgery $(21,22)$. Especially anterior knee pain felt during the activities in which excessive load is imposed on the knee joint is an indication of patellar instability (21) Etiology includes surgery techniques applied, position of the components, extensor mechanism imbalance and other reasons and malalignment of the components is the most important reason of patellar instability $(21,22)$. TT-TG distance is a measurement method preferred to assist the diagnosis and treatment of patellofemoral instability (13). In this study, it was determined that pre-op and post-op variation in the TT-TG distance was not meaningful in the patients with mid- and advanced level of knee osteoarthritis with whom TKA was performed.

In a study performed on 11 cadaver knees, Worden et al (23) 11 compared measurements of TT-TG distance and evaluated their reliability by means of direct graph, computerized tomography (CT) and anatomical dissection. They also evaluated whether the knee flexion and tibia rotation affected the measurement. As a result, it was observed that there was no difference in 
the measurement of TT-TG distance by means of CT and by means of anatomical dissection. It was concluded that knee flexion did not affect the measurement of TT-TG distance but tibia internal rotation reduced the measurement while external rotation increased the measurement. In our study, MRI was performed on the patients in neutral tibial rotation and extension position. In a study examining 11 patients, Schoettle et al (24) evaluated reliability of MRI in the measurement of TT-TG distance as compared to the CT. 12 knees of 11 patients were included into the study and in the measurements where bone signs were taken as reference, average TT-TG distance was found to be $14.4 \pm 5.4$ with $\mathrm{CT}$ and $13.9 \pm 4.5$ with MRI. When cartilaginous structures were taken as reference, results were $15.3 \pm 4.1$ with $\mathrm{CT}$ and $13.5 \pm 4.6$ with MRI imaging. As a result, it was concluded that in determining the TT-TG distance, measurements made with MRI imaging using bone or cartilaginous structures were reliable and additional CT scanning was not necessary. In our study, TT-TG distance was measured by taking cartilaginous structures as reference in the MRI images with no additional CT scanning performed and Pre-op TT-TG distance was found to be $8.83 \pm 3.54$ in average whereas Post-op TT-TG distance was found to be $8,30 \pm 3.89$ in average. In a study involving 100 patients, Pandit et al (15) evaluated normal TT-TG distance values on the MRI images and found $10 \pm 1 \mathrm{~mm}$, concluding that MRI imaging was a reliable measurement method.

In a study involving 120 patients, Dornacher et al (25) evaluated the correlation between TT-TG distance and patient's length and knee size. While MR imaging scan was performed on 60 patients due to trochlear displacement, MR imaging scan was performed on the other 60 patients because of a different pathology. TT-TG distance was measured and trochlear displacement was classified as high and low and trans-epicondyle distance was taken into account as the indication of the knee size. It was declared that there was no correlation between the TT-TG distance and knee size or body height but in a study comparing 45 patients aged between 20-14 having patellar instability with 180 patients having no instability complaints and used as control group, Pennock et al. (23)determined that with each $1 \mathrm{~cm}$ of increase in the body length, there was a $0.12 \mathrm{~mm}$ increase in the TT-TG distance. In our study, we assessed Pre-op TT-TG distances by dividing them into groups of body length, weight and BMI. While body length variable was not found affective on the TT-TG distance, it was seen that an increase in the body weight and BMI caused an increase in the TT-TG distance. However; as the distribution of TT-TG distances was imbalanced, this increase was thought to be related to the high chance factor. In a study performed by Pandit et al. (15), comparing 100 patients including 53 male and 47 female patients which arthroscopically proved that there was no osteoarthritic change with normal alignment, no correlation was found to exist between the TT-TG distance and sex. And also in our study, when we evaluated the patients by dividing them according to their sex, we observed that there was no correlation between the TT-TG distance and female-male sex.

In a study performed on 962 patients, Hochreiter et al. (13) retrospectively analyzed the TT-TG distance variation in patients with whom pre-op planning was made using approved commercial $3 \mathrm{~d}$ planning software and on whom TKP was performed. As a consequence, they found a wide range of TT-TG variation in osteoarthritic knees. They also found TT-TG distance to be more pathologic in valgus knees, concluding that with each 2 degrees of increase in the valgus degree, $1 \mathrm{~mm}$ increase occurred in the TT-TG distance, while TT-TG distance was not found to be pathological in varus knees even if deformity was more than 10 degrees. Sothey concluded that evaluating TT-TG distance in pre-op planning was important in the application of any individual TKP. And similarlyin our study, pre-op measured TT-TG distance showed a wide range of variation and it was seen that TT-TG distance was not affected when the alignment was less or more than 10 degrees. Besides that, in patients with varus alignment, pre-op and post-op TT-TG values were found to be within normal limits. In a study involving 175 cases and comparing pre-op TT-TG distances in patients with stage 3-4 osteoarthritis and patients with no osteoarthritis, Sahin et al. (14) determined that TT-TG distances measured in both groups was less than $20 \mathrm{~mm}$ and were also similar. Similarlyin our study, in patients with stage 3 and stage 4 osteoarthritis, pre-op and post-op TT-TG distances were found to be less than $20 \mathrm{~mm}$. Our study further showed that pre-op KSS and WOMAC scores were bad in the patients with stage 3-4 osteoarthritis and with a malalignment of more than 10 degrees as compared to the other group of patients. And in the patients with bad post-op KSS and WOMAC scores, there was a correlation with pre-op and post-op TT-TG distance range. In a study involving 85 patients on whom TKP was performed, Otsuki et al. (26) evaluated the correlation between varus malalignment and patellofemoral osteoarthritis. They also checked the pre-op TT-TG distance measurement of the patients and tilt of the patella. They concluded that in patients with varus malalignment, lateral patellofemoral osteoarthritis was specifically developed and there was a strong correlation between the TT-TG distance and patellar tilt. They also declared that patellar tilt and TT-TG distance were critical factors in patellofemoral osteoarthritis. In our 
study, pre-op and post-op TT-TG distance was found to be within normal limits in the patients with varus malalignment. Although pre-op and post-op TT-TG distance difference was not found to be statistically meaningful, we saw that TT-TG distance variation got better 2 times more in the patients whose varus alignment was 10 degrees or less as compared to the patients whose varus alignment was more than 10 degrees. It was noticeable that TT-TG distance variation increased with the reduction in varus alignment. In our study, we think that meaningful highness determined in the post-op TT-TG distance variation in the patients having high pre-op TT-TG distance could be related to the rotational changes in the tibial and femoral components in the knee prosthesis application and these changes caused variations in the TT-TG distance.

When pre-op TT-TG distance increases, post-op extension angle decreases. And when post-op TT-TG distance increases, post-op WOMAC score decreases. When pre-op and post-op TT-TG distance difference increases, post-op extension angle and post-op KSS knee function score decrease and post-op WOMAC score increases.

\section{CONCLUSION}

This study brings certain advantages and disadvantages. Since data was recorded prudentially in our study, there was no data loss. Although there are many studies in the literature about TT-TG distance, there is no study involving post-op TT-TG distance measurement in the patients on whom TKA was performed, and this factor increases the value of our study. Measurement of TT-TG distance on MRI images will surely have advantages since it will standardize the measurements and avoid additional radiation exposure with the patients. And there are also certain disadvantages as this technique is quite expensive and difficult to find. Besides that, all patients participating into the study were not operated by the same surgeon using a single type of prosthesis and number of female patients was more than the number of male patients because osteoarthritis is seen more commonly in women. However surplus in the number of female patients did not affect the results of this study because it did not cause any difference between the groups. Lack of patients with neutral or valgus alignment was another factor restricting the evaluation. As a result, although TT-TG distance showed a wide range of variation in stage 3-4 osteoarthritic knees, it was measured within the normal limits and decrease in the post-op TT-TG distance average was not statistically found to be meaningful. Since this is the first study in the literature about TT-TG distance measurement in TKP applications, we hope that it would shed some light to the future studies.
Abbreviations
OA - osteoarthritic
TKA — total knee arthroplasty
TT-TG - tibial tubercle-trochlear groove
JRM - joint range of motion
KSS - Knee Society Score
WOMAC - Western Ontario and McMaster Universities Osteoarthritis Index

Conflict of Interests: The authors declare that there are no conflicts of interest related to this article.

Funding: None

\section{Licensing}

This work is licensed under a Creative Commons Attribution 4.0 International (CC BY 4.0) License.

\title{
Sažetak
}

\section{DA LI PREOPERATIVNA TUBEROSITAS TIBIAE - TROHLEARNI ŽLEB DISTANCA UTIČE NA POSTOPERATIVNU PATELARNU NESTABILNOST KOD PACIJENATA SA ARTROPLASTIKOM KOLENA ZBOG SREDNJE UZNAPREDOVALOG OSTEOARTRITISA KOLENA?}

\author{
Turker Oguz, ${ }^{1}$ Cevik Nazan, ${ }^{1}$ Akalın Yavuz, ${ }^{1}$ Ozturk Alpaslan, ${ }^{1}$ Durmus Yavuz, ${ }^{2}$ Sahin Hikmet ${ }^{1}$ \\ ${ }^{1}$ Health Science University Bursa, Yuksek Ihtisas Research and Training Hospital, \\ Department of Orthopaedics and Traumatology, Bursa, Turkey \\ ${ }^{3}$ Health Science University Bursa Yuksek Ihtisas, Research and Training Hospital, \\ Department of Radiology, Bursa, Turkey
}

Uvod: Zbog određivanja tibijalni tuberkulum-trohlearni žleb distance preoperativno, kod pacijenata kojima će biti urađena totalna proteza kolena zbog srednjeg do uznapredovanog oblika osteoartritisa i uvida u postoperativne varijacije tibijalni tuberkulum-trohlearni žleb distance i procene da li je bilo uticaja na patelofemoral- 
nu nestabilnost koja bi se mogla razviti nakon operacije, 46 kolena planirana za totalnu protezu zbog srednje do uznapredovalog artritisa, su pregledana.

Metode: U preoperativnim i postoperativnim snimcima magnetske rezonance koja je rutinski rađena, izmerena je tibijalni tuberkulum-trohlearni žleb distanca. Kasnije je ispitano postoji li povezanost između tih preoperativnih i postoperativnih merenja i podataka zabeleženih pre operacije.

Rezultati: Nađeno je da je preperativna tibijalni tuberkulum-trohlearni žleb distanca bila $8,83 \pm 3,54$, dok je postoperativno iznosila $8,30 \pm 3,89$, uz preoperativnu-postoperativnu tibijalni tuberkulum-trohlearni žleb distanca varijaciju od 0,52 $\pm 3,64(\mathrm{p}=0,337)$. Kod pacijenata kod kojih je poravnanje bilo 10 stepeni ili manje, izmerena je preoperativna tibijalni tuberkulum-trohlearni žleb distanca $8,74 \pm 3,18$, a kod pacijenata čije je poravnanje bilo veće od 10 stepeni, iznosila je $8,89 \pm 3,83$ $(p=0,888)$. Kod pacijenata čiji je poravnanje bio 10

\section{REFERENCES}

1. Altman R, Asch E, Bloch D, Bole G, Borenstein D, Brandt K et al. Development of criteria for the classification and reporting of osteoarthritis. Classification of osteoarthritis of the knee. Diagnostic and Therapeutic Criteria Committee of the American Rheumatism Association. Arthritis Rheum. 1986; 29(8): 1039-49.

2. Zhang W, Moskowitz RW, Nuki G, Abramson S, Altman RD, Arden N et al. OARSI recommendations for the management of hip and knee osteoarthritis, Part I: Critical appraisal of existing treatment guidelines and systematic review of current research evidence. Osteoarthritis Cartilage. 2007; 15(9): 981-1000.

3. Ceyhan E, Gursoy S, Akkaya M, Ugurlu M, Koksal I, Bozkurt M. Toward the Turkish National Registry System: a prevalence study of total knee arthroplasty in Turkey. J Arthroplasty. 2016; 31(9): 1878-84.

4. Rand JA. Extensor mechanism complications after total knee arthroplasty. Instr Course Lect. 2005; 54: 241-50.

5. Tanikawa H, Tada M, Harato K, Okuma K, Nagura T. Influence of total knee arthroplasty on patellar kinematics and patellofemoral pressure. J Arthroplasty. 2017; 32: 280-5.

6. Barrack RL, Schrader T, Bertot AJ, Wolfe MW, Myers L. Component rotation and anterior knee pain after total knee arthroplasty: Clin Orthop Relat Res. 2001; 392: 46-55.

7. Nicoll D, Rowley DI. Internal rotational error of the tibial component is a major cause of pain after total knee replacement. J Bone Joint Surg Br. 2010; 92(9): 1238-44.

8. Camp CL, Heidenreich MJ, Dahm DL, Bond JR, Collins MS, Krych AJ. A simple method of measuring tibial tubercle to trochlear groove distance on MRI: description of a novel and reliable technique. Knee Surg Sports Traumatol Arthrosc. 2016; 24(3): 879-84.

9. Diederichs G, Issever AS, Scheffler S. MR Imaging of patellar instability: injury patterns and assessment of risk factors. Radio Graphics. 2010; 30(4): 961-81. stepeni ili manje, postoperativno je tibijalni tuberkulum-trohlearni žleb distanca iznosila 8,00 $\pm 2,85$, a kod pacijenata čije je poravnanje bio veće od 10 stepeni, iznosila je 8,52 4,52 ( $\mathrm{p}=0,661)$. Kod pacijenata čiji je poravnanje bilo 10 stepeni ili manje, varijacija je izražena kao $0,74 \pm 3,25$, a kod onih sa poravnanjem većim od 10 stepeni, iznosila je $0,37 \pm 3,95(\mathrm{p}=0,741)$.

Zaključak: Iako je zapažena tibijalni tuberkulum-trohlearni žleb distanca s velikom varijacijom kod osteoartritičnih kolena 3-4 stadijuma, ona je ipak bila u granicama normale i postoperativna varijacija je bila bez značaja. Budući da je ovo prva studija u literaturi o merenju tibijalni tuberkulum-trohlearni žleb distance kod totalne proteze kolena, nadamo se da će imati uticaja na slična istraživanja koja će se provoditi u budućnosti.

Ključne reči: biomehanika kolena, tibijalni tuberkulum, trohlearni žleb, totalna proteza kolena, patelarna nestabilnost.

10. Chhabra A, Subhawong TK, Carrino JA. A systematised MRI approach to evaluating the patellofemoral joint. Skeletal Radiol. 2011; 40(4): 375-87.

11. Cho WS, Woo JH, Park HY, Youm YS, Kim BK. Should the 'no thumb technique' be the golden standard for evaluating patellar tracking in total knee arthroplasty? The Knee. 2011; 18(3): 177-9.

12. Strachan RK, Merican AM, Devadasan B, Maheshwari R, Amis AA. A technique of staged lateral release to correct patellar tracking in total knee arthroplasty. J Arthroplasty. 2009; 24(5): 735-42.

13. Hochreiter B, Hirschmann MT, Amsler F, Behrend H. Highly variable tibial tubercle-trochlear groove distance (TT-TG) in osteoarthritic knees should be considered when performing TKA. Knee Surg Sports Traumatol Arthrosc. 2019; 27(5): 1403-9.

14. Sahin N, Atici T, Ozkaya G. Tibial Tuberosity-Trochlear Groove distance shows no change in patients with or without knee osteoarthritis. Eurasian J Med. 2018; 50(1): 38-41.

15. Pandit S, Frampton C, Stoddart J, Lynskey T. Magnetic resonance imaging assessment of tibial tuberosity-trochlear groove distance: normal values for males and females. Int Orthop. 2011; 35(12): 1799-803.

16. Anley CM, Morris GV, Saithna A, James SL, Snow M. Defining the role of the Tibial Tubercle-Trochlear Groove and Tibial Tubercle-Posterior cruciate ligament distances in the work-up of patients with patellofemoral disorders. Am J Sports Med. 2015; 43(6): 1348-53.

17. Carlson VR, Boden BP, Shen A, Jackson JN, Yao L, Sheehan FT. The Tibial Tubercle-Trochlear Groove distance is greater in patients with patellofemoral pain: implications for the origin of pain and clinical interventions. Am J Sports Med. 2017; 45(5): 1110-6.

18. Canale ST. Campbell's Operative Orthopaedics. 10th ed. Elsevier, 2003

19. Kinds MB, Welsing PMJ, Vignon EP, Bijlsma JWJ, Viergever MA, Marijnissen ACA et al. A systematic review of the 
association between radiographic and clinical osteoarthritis of hip and knee. Osteoarthritis Cartilage. 2011; 19(7): 768-78.

20. Motsis EK, Paschos N, Pakos EE, Georgoulis AD. Review article: patellar instability after total knee arthroplasty. J Orthop Surg. 2009; 17(3): 351-7.

21. Worden A, Kaar S, Owen J, Cutuk A. Radiographic and anatomic evaluation of tibial tubercle to trochlear groove distance. J Knee Surg. 2016; 29(7): 589-93.

22. Petersen W, Rembitzki IV, Bruggemann GP, Ellermann A, Best R, Koppenburg AG et al. Anterior knee pain after total knee arthroplasty: a narrative review. Int Orthop. 2014; 38(2): 319-28.

23. Pennock AT, Alam M, Bastrom T. Variation in tibial tubercle-trochlear groove measurement as a function of age, sex, size, and patellar instability. Am J Sports Med. 2014; 42(2): 389-93.

24. Schoettle PB, Zanetti M, Seifert B, Pfirrmann CWA, Fucentese SF, Romero J. The tibial tuberosity-trochlear groove distance; a comparative study between CT and MRI scanning. Knee. 2006; 13(1): 26-31.

25. Dornacher D, Reichel H, Kappe T. Does tibial tuberosity-trochlear groove distance (TT-TG) correlate with knee size or body height? Knee Surg Sports Traumatol Arthrosc. 2016; 24(9): 2861-7.

26. Otsuki S, Nakajima M, Okamoto Y, Oda S, Hoshiyama $\mathrm{Y}$, Iida $\mathrm{G}$ et al. Correlation between varus knee malalignment and patellofemoral osteoarthritis. Knee Surg Sports Traumatol Arthrosc. 2016; 24(1): 176-81.

\section{Correspondence to/Autor za korespondenciju}

Nazan Cevik

Health Science University Bursa YuksekIhtisas

Research and Training Hospital

Department of Orthopaedics and Traumatology, 16310, Yildirim, Bursa, Turkey

nazancevik@gmail.com 